\title{
Erratum to: Determinants of urinary albumin excretion within the normal range in patients with type 2 diabetes: the Randomised Olmesartan and Diabetes Microalbuminuria Prevention (ROADMAP) study
}

E. Ritz • G. C. Viberti • L. M. Ruilope • A. J. Rabelink •

J. L. Izzo Jr • S. Katayama • S. Ito • A. Mimran •

J. Menne $\cdot$ L. C. Rump $\cdot$ A. Januszewicz $\cdot$ H. Haller

Published online: 1 December 2009

(C) Springer-Verlag 2009

\section{Erratum to: Diabetogia}

DOI 10.1007/s00125-009-1577-3

Unfortunately, Professor L. C. Rump's address was listed incorrectly on the original version of this paper. The correct address is given below.

The online version of the original article can be found at http://dx.doi. org/10.1007/s00125-009-1577-3.

\section{E. Ritz}

Department of Nephrology, University of Heidelberg,

Heidelberg, Germany

G. C. Viberti

KCL Guy's Hospital,

London, UK

L. M. Ruilope

Division of Hypertension, Hospital 12 de Octubre,

Madrid, Spain

\section{A. J. Rabelink}

Department of Nephrology and Hypertension,

Leiden University Medical Center,

Leiden, the Netherlands

\section{J. L. Izzo Jr}

Department of Medicine, Erie County Medical Center,

Buffalo, NY, USA

\section{S. Katayama}

The Fourth Department of Medicine, Saitama Medical School,

Saitama, Iruma, Japan
S. Ito

Department of Clinical Medicine, Division of Nephrology,

Endocrinology and Vascular Medicine,

Tohoku University Graduate School of Medicine,

Sendai, Japan

A. Mimran

Hospital Lapeyronie,

Montpellier, France

L. C. Rump

Department of Nephrology,

Heinrich-Heine-University Düsseldorf,

Düsseldorf, Germany

A. Januszewicz

Department of Hypertension, Institute of Cardiology,

Warsaw, Poland

J. Menne $\cdot$ H. Haller $(\square)$

Department of Nephrology and Hypertension,

Hanover Medical School,

Carl-Neuberg Str. 1,

30625 Hannover, Germany

e-mail: haller.hermann@mh-hannover.de 